\title{
UJI VALIDITAS DAN RELIABILITAS UNTUK MAHASISWA SEMESTER VI (ENAM) FAKULTAS ILMU BUDAYA UNIVERSITAS LANCANG KUNING
}

\author{
Oleh : \\ Yuhelmi, Rismayeti
}

\begin{abstract}
ABSTRAK
Berdasarkan temuan kami dilapangan masih banyak mahasiswa yang belum mengerti dan belum bisa menggunakan SPSS (Statistical Product And Service Solution) terutama dalam melakukan Uji Validitas dan Reliabilitas dimana kuesioner yang dibuat harus diujikan terlebih dahulu sebelum di digunakan dalam pengolahan data-data mereka untuk menyelesaikan tugas akhir, sehingga banyak yang menggunakan jasa seseorang untuk membuatkannya. Disamping itu kami dari tim pengabdian merasa terpanggil untuk dapat melaksanakan pengabdian masyarakat ini karena merasa bertanggung jawab atas keberhasilan mahasiswa kita dalam pendidikan dengan pemanfatan teknologi komputer, disamping itu saya selaku dosen pengampu mata kuliah Metode Penelitian harus mampu mentransfer ilmu yang saya miliki sehingga mereka dapat menyelesaikan tugas akhir tepat waktu tanpa bantuan jasa orang lain serta akan dibawa nantinya dalam dunia kerja. Adapun rancangan Ibm yang akan dilaksanakan adalah 1. Pengenalan dan pemberian materi pelatihan. 2.Penyampaian materi pelatihan, 3. Pemberian Praktik dengan komputer, 4. Evaluasi. Setelah pelatihan dilaksanakan didapat bahwa pemahaman mereka tentang Uji validitas dan reliabilitas menggunakan SPSS semakin meningkat ini terlihat dengan membandingkan hasil pretest dan postes kemudian setelah dijelaskan dan dipraktekkan, sampai mereka paham melakukan perhitungan Uji Validitas dan reliabilitas dengan SPSS, agar mereka dapat mempersiapkan diri dalam menyusun tugas akhir dan memotivasi mereka dalam menggunakan SPSS untuk mengolah data.
\end{abstract}

Kata Kunci : Uji Validitas Dan Reliabilitas, SPSS, Fakultas Ilmu Budaya

\section{PENDAHULUAN}

\subsection{Analisis Situasi}

Tak bisa dibantah jika kita mengolah data statistik dengan komputer maka yang pertama kali terbayang adalah SPSS. SPSS memang salah satu program statistik yang paling populer di antara program lainnya. SPSS banyak digunakan dalam penelitian-penelitian sosial dan riset, yang sesuai dengan kepanjangan SPSS yaitu: Statistical Package for the Social Science. Walaupun sekarang singkatannya menjadi Statistical Product and Service Solution (karena 
fungsinya yang lebih berkembang) namun tetap saja SPSS lebih sering digunakan dalam penelitian sosial. Banyak persoalan, apakah itu hasil penelitian, riset ataupun pengamatan, baik yang dilakukan khusus ataupun berbentuk laporan, dinyatakan dan dicatat dalam bentuk bilangan atau angka-angka. (Yuhelmi,2015:1).

Sebetulnya pengolahan dilakukan tanpa menggunakan SPSS pun bisa tapi akan memakan waktu yang lama dalam mengolah data-data tersebut tetapi sesuai dengan perkembangan Ilmu Pengetahuan dan Teknologi Informasi yang sangat cepat berkembang sekarang ini rasanya amat fatal dan kata orang sangat aneh kalau data-data yang jumlahnya tidak sedikit itu diolah secara manual, jadi mau tidak mau kita selaku generasi penerus bangsa harus bisa mengikuti perkembangan teknolgi tersebut, salah satunya adalah memanfaatkan software pengolah data, yang akan kami berikan pelatihan tersebut kepada Mahasiswa Semester VI (Enam) Fakultas Ilmu Budaya Universitas Lancang Kuning.

Berdasarkan temuan kami dilapangan masih banyak mahasiswa Fakultas Ilmu Budaya yang belum mengerti dan belum bisa menggunakan SPSS tersebut dalam mengolah data-data mereka terutama untuk melakukan uji validitas dan reliabilitas.

Sugiyono dan Wibowo (2004) menjelaskan, instrumen yang valid adalah alat ukur yang digunakan untuk mendapatkan data yang valid dan dapat digunakan untuk mengukur apa yang hendak diukur. Instrumen yang reliabel berarti instrumen tersebut bila digunakan beberapa kali untuk mengukur obyek yang sama akan menapatkan hasil yang sama. Reliabilitas adalah seberapa besar kemampuan kuisioner memberikan hasil penelitian yang konsisten.

Jika untuk menyelesaikan tugas akhir apabila tugas akhir itu mengunakan data-data yang harus diolah, maka banyak yang menggunakan jasa seseorang untuk membuatkan olahan data tersebut karena mereka tidak faham dan tidak mengerti menggunakan SPSS maupun program pengolah data lainnya, inilah yang melatar belakangi Tim untuk melakukan pelatihan tersebut.

\subsection{Permasalahan Mitra}

a. Belum adanya pelatihan dan sosialisasi tentang Uji Validitas Dan Reliabilitas.

b. Masih Minim pengetahuan tentang cara membuat kuesioner.

c. Mahasiswa masih menganggap sulit dalam melakukan Uji Validitas dan Reliabilitas. 
Disamping itu kami dari tim pengabdian merasa terpanggil untuk dapat melaksanakan pengabdian masyarakat ini karena merasa bertanggung jawab atas keberhasilan mahasiswa kita dalam pendidikan dengan pemanfaatan teknologi komputer ini, yang akhirnya dapat dipergunakan dalam penyusunan tugas akhir, dan juga yang akan dibawa nantinya dalam dunia kerja.

Sekali lagi kami dari tim pengabdian dilapangan menemukan masih banyak mahasiswa yang bingung dalam mengolah data dengan SPSS, sehingga sampai saat ini masih belum menemukan solusi yang tepat untuk mengatasi masalah tersebut.

Berdasarkan Kondisi seperti ini maka kami ingin mengadakan pengabdian masyarakat sebagai bagian dari Tri Darma Perguruan Tinggi dengan judul " Pelatihan Uji Validitas Dan Reliabilitas Untuk Mahasiswa Semester VI (Enam) Fakultas Ilmu Budaya Universitas Lancang Kuning”, pelatihan ini sangat penting untuk meningkatan kemampuan mahasiswa dalam membuat kuesioner dan mengolah data saat akan menyelesaikan tugas akhir.

\section{SOLUSI DAN TARGET LUARAN}

\subsection{Solusi yang ditawarkan}

Terkait permasalahan mitra dibutuhkan solusi dalam aspek pemberian materi tentang pentingnya Kuesioner yang valid dalam penelitian. Pelatihan tentang Uji validitas dan Reliabilitas ini bertujuan meningkatkan pengetahuan mahasiswa dalam membuat kuesioner, guna membantu mahasiswa dalam membuat tugas akhir. Untuk meningkatkan hasil penelitian yang lebih baik maka perlu adanya pelatihan ini dengan aspek penerapannya sebagai berikut :

a. Mempersiapkan diri untuk penyusunan skripsi.

b. Memberikan pelatihan Uji Validasi dan Reliabilitas

c. Meningkatkan kemampuan Mahasiswa dalam menggunakan Program SPSS serta dapat menginstal program SPSS pada komputer sendiri. 


\subsection{Target Luaran}

Dengan demikian diharapkan para mahasiswa tersebut punya kemampuan melakukan uji validitas dan reliabilitas, terutama hal-hal sebagai beikut :

a. Mahasiswa Mampu Melakukan Uji Validitas dan reliabilitas

b. Dapat meningkatkan kemampuan dalam menggunakan SPSS

Tabel. 1 Target Luaran

\begin{tabular}{|c|c|c|c|}
\hline No & \multicolumn{2}{|c|}{ Jenis Luaran } & Indikator Capaian \\
\hline \multirow{2}{*}{1} & \multirow{2}{*}{ Publikasi ilmiah ${ }^{2)}$} & Internasional & \\
\hline & & Nasional Terakreditasi & submit \\
\hline \multirow{2}{*}{2} & \multirow{2}{*}{$\begin{array}{l}\text { Pemakalah dalam temu } \\
\text { ilmiah }^{3)}\end{array}$} & Internasional & \\
\hline & & Nasional & Terdaftar \\
\hline 3 & \multicolumn{2}{|c|}{ Model/Purwarupa/Desain/Karya seni/ Rekayasa Sosial ${ }^{8)}$} & Produk \\
\hline 4 & \multicolumn{2}{|l|}{ Buku Ajar (ISBN) $)^{9)}$} & Draft \\
\hline 5 & \multicolumn{2}{|c|}{ Tingkat Kesiapan Teknologi $(\mathrm{TKT})^{10)}$} & 7 \\
\hline
\end{tabular}

\section{METODE PELAKSANAAN}

Kegiatan IbM dilakukan kapada mitra yaitu Mahasiswa Semester VI (Enam) Fakultas Ilmu Budaya Universitas Lancang Kuning.

\section{Pelatihan dan Penyuluhan tentang Uji Validitas Dan Reliabilitas}

Kegiatan pelatihan yang dilakukan pengusul kepada mitra Ibm adalah membagikan angket/ kuesioner kepada kedua mitra untuk mengetahui dasar pengetahuan mereka terhadap materi yang akan disampaikan, lalu menstransfer informasi tentang tata cara bagaimana mengolah data menggunakan Uji Validitas Dan Reliabilitas. Pada saat pengusul melakukan survey di lokasi Ibm diketahui bahwa para mahasiswa belum banyak yang paham bagaimana Uji Validitas Dan Reliabilitas dengan SPSS karena tidak semua mampu belajar mandiri.

\section{Pelatihan untuk pemahaman}


Dalam pelatihan untuk pemahaman ini mitra di beri pengetahuan tentang bagaimana cara melakukan trasformasi data agar pengolahan data menjadi mudah dan sederhana, yang diperagakan dan dipresentasikan, diberikan oleh tim Unilak kepada mitra kemudian dilakukan juga sesi tanya jawab.

Mitra dilatih melakukan pemahaman dahulu agar nantinya tidak sulit dalam sesi Pratikum.

\section{Pratikum Uji Validitas Dan Reliabilitas}

Disini mitra diajak untuk mempraktekan bagaimana cara melakukan Uji Validitas Dan Reliabilitas dengan SPSS tersebut, agar mahasiswa mengerti dan mampu melakukannya sendiri saat membuat skripsi nanti, masing-masing peserta diberi kesempatan untuk dapat mempraktekannya, sehingga instruktur dapat melihat sampai dimana kemampuan yang sudah dimiliki oleh Mahasiswa tersebut.

\section{Evaluasi hasil.}

Setelah pelatihan juga akan disebar angket untuk melihat pencapaian hasil pelatihan. Evaluasi hasil dapat diketahui dengan membandingkan hasil pretest dan postest dari kuesioner yang telah diisi oleh mitra, kemudian diolah untuk dapat disimpulkan.

\section{KELAYAKAN TIM PELAKSANA}

Tim memiliki bidang keahlian berbeda yang saling menunjang dalam kegiatan Ipteks bagi Masyarakat (IbM) untuk Uji validitas dan reliabilitas. Berdasarkan tabel dibawah dapat dilihat kepakaran dari tim :

Tabel 2. Kepakaran dan Tugas Tim dalam Kegiatan

\begin{tabular}{|l|l|l|l|}
\hline No & Nama/Unit Kerja & Pendidikan/Keahlian & Tugas dalam kegiatan \\
\hline 1. & Yuhelmi, M.Kom & Bidang Komputer & $-\begin{array}{l}\text { Koordinator } \\
\text { tenanggung jawab } \\
\text { terlaksananya } \\
\text { pengabdian dengan } \\
\text { lancar }\end{array}$ \\
\hline & & & $\begin{array}{l}\text { Penanggung jawab } \\
\text { pelatihan teknis }\end{array}$ \\
\hline
\end{tabular}




\begin{tabular}{|l|l|l|l|}
\hline 2 & Rismayeti, M.IP & Bidang Ilmu & $\begin{array}{l}\text { pengolahan dan } \\
\text { pembuatan materi } \\
\text { Perpustakaan } \\
\text { pelatihan }\end{array}$ \\
& & & $-\begin{array}{l}\text { Penanggung jawab } \\
\text { persiapan pelatihan } .\end{array}$ \\
\hline
\end{tabular}

Adapun Yuhelmi, M.Kom adalah dosen Tetap Universitas Lancang Kuning pengampu mata Kuliah Metode Penelitian di Fakultas Ilmu Budaya Universitas Lancang Kuning selain itu beliau juga pernah mengampu mata kuliah pengantar komputer di Fakultas Ekonomi selama 14 tahun, dimana 5 tahun terakhir materi pembelajarannya menitik beratkan pada program aplikasi SPSS dimana salah satu Sub Pokok Bahasan materinya adalah Uji Validitas Dan Reliabilitas, jadi tidak diragukan lagi untuk kepakarannya.

Sedangkan Rismayeti, M.IP adalah Dosen Tetap Di Fakultas Ilmu Budaya Universitas Lancang Kuning dari tahun 2009 sehingga kepakarannya juga tidak diragukan lagi, dimana keduanya saling bersinergi dalam pencapaian visi dan misi Fakultas Ilmu Budaya.

\section{HASIL DAN LUARAN YANG DICAPAI}

\subsection{Hasil yang dicapai}

Kegiatan ini dilaksanakan pada ruang jurusan Ilmu Perpustakaan pada tanggal 10 April 2017, yang dihadiri oleh 30 peserta, berdasarkan kegiatan yang telah dilaksanakan, beberapa hasil telah diperoleh.

Pada tahap pertama, peserta dibagikan kuesioner pretest untuk diisi peserta setelah itu instruktur menjelaskan teori tentang Cara Instalasi Program SPSS dan Pengertian uji validitas dan reliabilitas serta arahan cara bagaimana melakukan Uji validitas dan Reliabilitas dengan SPSS, sehingga peserta memperoleh pemahaman tentang konsep dasar Uji validitas dan Reliabilitas. 
Pada tahap kedua, peserta diajak untuk pemahaman terhadap materi yang telah disampaikan dan dipresentasikan oleh Tim FIB, kemudian pada sesi ini juga dibuka sesi tanya jawab terlihat semua peserta antusias untuk bertanya bahkan tim sedikit agak kerepotan dalam melayani yang bertanya mengenai kesulitan yang selama ini mereka hadapi dilapangan untuk mengolah data. Kemudian Tim FIB menjelaskan salah satunya yaitu dengan berlatih dan praktek sesering mungkin dan dengan sebaik-baiknya,akan mendapatkan hasil yang bagus dan mereka nantinya mampu tanpa harus melihat buku panduan lagi, sehingga dengan demikian mereka akan mampu untuk melakukan Uji validitas dan Reliabilitas dengan mudah.

Pada tahap terakhir, setelah peserta memiliki ketrampilan dalam Pengolahan data, tim meminta kepada semua peserta yang ikut agar dapat menerapkan ilmunya dan menularkan kepada teman-teman yang lain.

Setelah peserta memahami dasar-dasar teknik melakukan uji validitas dan reliabilitas sebelum pengolahan data, pada tahap ini peserta diminta bagi yang sudah paham untuk dapat memberitahukan kepada peserta lain yang belum begitu mengerti tentang materi yang telah dibahas.

Sesi berikutnya adalah sesi praktik melakukan bagaimana Uji validitas dan reliabilitas dilakukan dengan spss, setiap peserta diberi kesempatan untuk mempraktekkan langsung kemudian dilanjutkan dengan sharing sesama peserta lainnya.

Sesi terakhir adalah sesi tanya jawab. Pada sesi ini peserta diberikan kesempatan untuk menanyakan dan menanggapi mengenai teori yang telah dipaparkan sebelumnya. Peserta terlihat antusias untuk menanyakan hal-hal yang berkaitan dengan tema pelatihan. Menurut mereka hal ini merupakan sesuatu yang menarik, terutama mengenai kegiatan praktik langsung dipandu dan disimulasikan.

Suatu pelatihan tidak akan berhasil dan kelihatan hasilnya jika tidak dibarengi dengan kemauan pada masing-masing peserta. Untuk itu, peserta diberi keyakinan bahwa hasil yang memuaskan tidak akan muncul begitu saja dengan mudah, tetapi diperlukan konsistensi dan keyakinan bahwa sesederhana apapun kegiatan yang dilakukan jika diikuti dengan keyakinan yang kuat maka akan memberikan hasil yang memuaskan. 


\subsection{Luaran yang dicapai}

Evaluasi, ini diperoleh hasil olahan kusioner yakni dengan memberikan kuesioner pada peserta sebelum dan sesudah pelatihan, kemudian dari jawaban kuesioner yang diberikan akan kelihatan perbandingan pengetahuan perserta sebelum dan sesudah pelatihan, lalu ditarik kesimpulan dari hasil yang diperoleh, dari hasil kuisioner tersebut dapat diketahui bagaimana pemahaman peserta terhadap materi yang diberikan selama pelatihan.

Untuk lebih jelasnya dapat dilihat hasil rekapitulasi jawaban responden :

Tabel 3. Hasil Rekapitulasi Kuesioner pretest

\begin{tabular}{|l|l|c|c|c|}
\hline No & Item Pertanyaan & Benar & Salah & Kosong \\
\hline 1. & Apa yang dimaksud dengan uji validitas & 5 & 6 & 19 \\
\hline 2. & Apa yang dimaksud dengan uji reliabilitas & 2 & 8 & 20 \\
\hline 3. & Kapan saatnya data tersebut dapat dikatakan valid & 0 & 8 & 22 \\
\hline 4. & Kapan saatnya data tersebut dapat dikatakan reliabel & 0 & 4 & 26 \\
\hline 5. & Bagaimana tingkatan reliabel menurut Triton & 0 & 0 & 30 \\
\hline 6. & Kapan saatnya dilakukan uji validitas dan reliabilitas & 0 & 3 & 27 \\
\hline
\end{tabular}

Berdasarkan tabel diatas dapat diketahui bahwa banyak item pertanyaan yang tidak terjawab atau kosong disini dapat kita simpulkan bahwa para peserta masih minim pengetahuannya tentang uji validitas dan reliabilitas.

Misalnya untuk item pertanyaan "Apa yang dimaksud dengan Uji validitas dan reliabilitas", dari jawaban kuesioner yang diolah bahwa dari 30 peserta hanya 5 orang yang jawabanya benar, 6 orang yang jawabannya salah dan 19 orang tak mengisi jawaban, jadi dapat disimpulkan sebahagian besar belum mengerti apa itu Uji validitas. Tetapi setelah dilakukan pelatihan sebagian besar mengatakan mengerti dengan Uji validitas dan reliabiitas, ini menunjukan bahwa pelatihan tersebut berhasil.

Selanjutnya untuk item pertanyaan "Kapan saatnya Kapan saatnya data tersebut dapat dikatakan valid", dari 30 peserta satupun tidak ada jawaban yang benar, dimana 3 orang menjawab salah dan 27 orang tidak menjawab atau kosong, kemudian setelah dilakukan pelatihan, hampir seluruh dapat menjawab dengan benar ternyata dari pelatihan yang 
sederhana ini akan membantu mahasiswa menyelesaikan kuliah tepat waktu dapat diihat dari hasil olahan kuesioner dibawah ini.

Tabel 4. Hasil Rekapitulasi Kuesioner posttest

\begin{tabular}{|l|l|r|c|c|}
\hline No & Item Pertanyaan & Benar & Salah & Kosong \\
\hline 1. & Apa yang dimaksud dengan uji validitas & 28 & 2 & 0 \\
\hline 2. & Apa yang dimaksud dengan uji reliabilitas & 28 & 2 & 0 \\
\hline 3. & Kapan saatnya data tersebut dapat dikatakan valid & 25 & 5 & 0 \\
\hline 4. & Kapan saatnya data tersebut dapat dikatakan reliabel & 26 & 4 & 0 \\
\hline 5. & Bagaimana tingkatan reliabel menurut Triton & 27 & 3 & 0 \\
\hline 6. & Kapan saatnya dilakukan uji validitas dan reliabilitas & 29 & 1 & 0 \\
\hline
\end{tabular}

Jadi berdasarkan kedua tabel diatas dapat kita lihat meningkatnya kemampuan peserta setelah pelatihan diberikan.

Hasil dari pengabdian ini menunjukkan bahwa Pelatihan yang telah dilaksanakan tersebut berhasil dengan ukuran keberhasilan :

1. Jumlah peserta melebihi kuota yang tersedia yaitu 30 orang peserta. (dapat dilihat daftar hadir)

2. Hasil olahan data ( pretest dan posttes) menunjukan peningkatan kemampuan peserta (dapat dilihat pada pembahasan).

\section{SIMPULAN}

Pelatihan Uji validitas dan reliabiitas dengan SPSS ini membekali para mahasiswa :

1. Pengetahuan mengolah data dengan cepat, tepat dan akurat.

2. Pelatihan ini dapat memotivasi mereka agar tidak bingung lagi saat akan menyusun kuesioner tugas akhir.

3. Kegiatan ini sangat tepat dilakukan guna mendukung mahasiswa yang akan melakukan penulisan tugas akhir agar mereka dapat terbantu dalam hal mengolah data.

\section{DAFTAR PUSTAKA}


Aima Havis. 2006. Statistik, Penerbit Candra Pratama Jakarta.

Djarwanto dan Pangestu Subagyo. 1996. Statistik Induktif, Edisi Keempat, Yogyakarta:BPFE

Elcom. 2011.Belajar Kilat SPSS 17, Andipublisher

Hasan, I. 2004. Statistik Deskriptif.http//id.wikipedia.org/wiki/ Statistika_deskriptif.

Santoso, S.2006. Menguasai Statistik di era Informasi dengan SPSS 14. Jakarta:PT Elex Media Komputindo.

Santoso, Singgih. 2004.Latihan SPSS Statistik Multivariat,Jakarta : Elex Media Komputindo.

Sudjana. 1996. Metode Statististika. Edisi ke 6. Bandung:’Tarsito"

Syekh, Sayid. 2011. Pengantar Statistik Ekonomi Dan Sosial.Gaung Persada Press Jakarta.

Teguh Handoyo. 2009. 25 Model Analisis Statistik dengan SPSS 17.Elex Media Komputindo.

Yuhelmi, Yuhelmi. "TRANSFORMASI DATA PENELITIAN DENGAN SPSS UNTUK MAHASISWA SEMESTER V (LIMA) DAN SEMESTER VII (TUJUH) FAKULTAS ILMU BUDAYA DAN FAKULTAS EKONOMI UNIVERSITAS LANCANG KUNING." INA-Rxiv, 24 July 2018. Web.. 